\title{
The Survey of Obsessive-Compulsive Disorder Symptoms in Patients with Multiple Sclerosis and Its Association with Eating Attitudes
}

\section{Shahla Mohamadirizi*}

Faculty of Nursing, Isfahan University of Medical Sciences, Isfahan, Iran

\begin{abstract}
Context: Multiple Sclerosis and its treatments have been shown to have a negative psychological effect on many MS patients. Infact living with a chronic disease with an unpredictable outcome may cause psychiatric symptoms such as Obsessive-Compulsive disorder and serious impairment in eating attitudes Therefore, this study was designed with the aim of determinating of Obsessive-Compulsive Disorder Symptoms in patients with Multiple Sclerosis and its association with eating attitudes
\end{abstract}

Materials and methods: This was a descriptive correlational study which was conducted in MS clinic located at the Ayatollah Kashani Hospital affiliated to Isfahan University of Medical Sciences, Iran, in 2013. Of MS patients in remitting course that referred to MS clinic Two hundred and ten patients were selected and completed Demographic characteristic questionnaire, Eating Disorder Examination Questionnaire (EDE-Q) and Maudsley ObsessiveCompulsive Questionnaire. The SPSS software, version11, was used to conduct statistical tests including t-test, ANOVA and Pearson correlation.

Results: The mean scores of age, body mass index (BMI) and duration of illness were (33.96 \pm 9.5$)$ Years (21.6 $\pm 3.6) \mathrm{Kg} . \mathrm{m} 2$ and $(24.3 \pm 6.3)$ months, respectively. Most patients were married $(66.1 \%)$, without university education $(62.8 \%)$ and with moderate incomes $(63 \%)$. Majority of the patients had received beta-interferon) $(65 \%)$ as their main treatment. In addition, mean \pm SD of eating disorder and Obsessive-Compulsive disorder scores were $4.9 \pm$ 0.8 and17.6 \pm 4.5 , respectively. Also $48.1 \%$ of MS patients had the Obsessive-Compulsive disorder symptoms and $19.1 \%$ showed eating disorder. There was a significant positive correlation between the Obsessive-Compulsive score and eating disorder scores $(r=0.32, p \leq 0.05)$.

Conclusion: The findings of this study showed that majority of the patients with MS had experienced symptoms of eating disorders and Obsessive-Compulsive disorder. The findings of this study can assist health care team in order to pay more attention to eating disorders and Obsessive-Compulsive disorder in patients with multiple sclerosis and also considering nutritional problems during disease in their evaluations. Furthermore there was correlation between the Eating Disorder Symptoms and Obsessive Compulsive in MS patients. Also patient education by nurses regarding nutritional problems in during disease can be effective in early diagnosing and identifying such disorders.

Keywords: Eating disorder; Obsessive-compulsive disorder; Multiple sclerosis

\section{Introduction}

With no clear cause, multiple sclerosis (MS) is the most common inflammatory demyelinating disease which affects the central nervous system [1]. The signs and symptoms of this disease severely damage one's daily activities in such a way that, in its worst form, can limit one's independence. In spite of the fact that dealing with such diseases- which threaten the ability of the patients to perform hard work a majority of these patients seems to be unable to do so; therefore, their personal and social life would be exposed to danger or they would face important mental changes [2]

According to the studies, it is proven that neurological signs and symptoms among the patients with MS are directly related to the psychological problems as depression, anxiety, and emotional disability. Statistically, it is indicated that about $30 \%$ of MS patients had experienced the psychiatric problems [3]. Obsessive-Compulsive Disorder (OCD) and eating disorder are the two common psychiatric problems which have a great impact on the quality of the life of MS patients.

Limited researches, so far, have been done, focusing on these two disorders. According to these studies it was proven that about $45 \%$ of MS patients had experienced the OCD during their illness [4]. Shabani et al. in their study pointed out that $17.5 \%$ of MS patients had suffered from OCD and about $69.2 \%$ from depression [5].

Obsessive-compulsive disorder (OCD) is a kind of psychosis- neurotic disease which is characterized by, persistent intrusive thoughts (obsessions), and repeated behaviors (compulsion) which typically result in a short-lived relief of anxiety. People with OCD generally recognize their obsessions and compulsions as irrational and feel distressed by these realization $[6,7]$.

Considering the eating disorder, also, studies indicate that it is generally increasing amongst the people these days. People with eating disorders suffer from too much attention to the food and the weight and shape of their body. Types of these disorders are anorexia and bulimia based on the fourth category of mental disorders [8]. Eating disorders (EDs) are public health problems; however, patients with chronic diseases are more likely to exhibit two or more disturbed eating behaviors than their peers without chronic diseases. In other words patients with chronic diseases are 2.4 times more at the risk of eating disorders and 1.9 times more at the risk of eating disorder subgroups compared with those without the disease [9]. In this regard in MS

*Corresponding author: Shahla Mohamadirizi, Facility of Nursing, Isfahan University of Medical Sciences, Isfahan, Iran, Tel: 09103142630; E-mail: mohamadirizi@nm.mui.ac.ir

Received June 22, 2016; Accepted July 23, 2016; Published July 30, 2016

Citation: Mohamadirizi S (2016) The Survey of Obsessive-Compulsive Disorder Symptoms in Patients with Multiple Sclerosis and Its Association with Eating Attitudes. J Mult Scler (Foster City) 3:179. doi:10.4172/2376-0389.1000179

Copyright: ( 2016 Mohamadirizi S. This is an open-access article distributed under the terms of the Creative Commons Attribution License, which permits unrestricted use, distribution, and reproduction in any medium, provided the original author and source are credited. 
patients, the occurrence of some specific situations such as overemphasis on food, special dietary patterns, periods of increasing and decreasing weight and the subsequent consequences, usage of restrictive diets and existence of some of restrictions can create the context for the onset and progression of eating disorders in these patients. People with eating disorders demonstrate behaviors about the misunderstanding of the shape and weight of their body [10]. Therefore, many people who suffer from these disorders may have low self-esteem and preoccupation about their appearance [11]. Some studies have shown that people with eating disorders suffer more from feelings like depression, loneliness, isolation, low self-esteem and obsession [12]. Also According to the different studies, it has been proven that there is a direct relationship between the psychological disorders, such as depression and different anxieties and nutritional disorders. While the nature of such role is not known, yet, many theories focus on the psychological disorders as the main cause of the nutritional disorders. Many epidemiologic and clinical studies showed that majority of the people with any kind of eating disorder had been affected by one, or more than one, anxiety disorders [13]. In this regard Fitzsimmons (2011) reported that $1 / 2$ of people with eating disorder had been affected by one or more than one anxiety disorder, amongst whom $41 \%$ showed OCD, too [13].

Generally, people who have anxiety about their bodies and images are more exposed to behaving in such a way that can change the people's negative assessment about their bodies. Such behaviors, therefore, can pave the way for causing eating disorder. Angel, in his study, showed that aged girls, tall ones, and those with a high level of anxiety were more dissatisfied about their bodies and, hence, they were more affected by eating disorders [14]. Of people with eating disorder, $20 \%$ in Kaye's study were suffering from anxiety disorder, too [14]. Limited studies have focused on the obsessive-compulsive disorder, eating disorder and the relationship of these two with people with MS. MS disease can probably influence type and severity of communication, eating disorders and obsessive-compulsive behavior in a different way compared to non-patients. Therefore, we decided to conduct a study with the purpose of considering eating disorder and its relationship with obsessive-compulsive in patients with MS who were admitted to the Kashani hospital, affiliated with the Isfahan University of Medical Sciences in 2013.

\section{Methods}

A cross-sectional study was performed on 210 patients with MS during their course of recovery. The study was conducted since June to August 2013. Sample size was calculated based on a previous study in which eating attitudes and anxiety disorder was investigated and a correlation of 0.2 was reported between these two variables [15]. Then, using the following formula and parameters, $n=(Z 1+Z 2) Z$ $(1-r 2) 2 \div \mathrm{r} 2+2 ; Z=1.96, Z 2=84 \%, r=0.2$, a total of 200 subjects was estimated to be needed to study the correlation between eating attitudes and Obsessive- Compulsive disorder. After approval of the research by the ethics committee of Isfahan University of Medical Sciences, initially, the researcher chose the eligible patients based on having the inclusion criteria. The purpose of conducting the research was explained for them. Subsequently, written informed consents have been obtained from the participants.

The inclusion criteria were as follows: age of 18 to 65 years (age of less than 18 years is associated with period of adolescence and can be affective on the mood, and age of after 65 years can change physical and mental abilities), definitive diagnosis of MS by the physician, ability to read and write in Persian language, extending a minimum of two months from diagnosis (due to mental stability), ability to eat and drink, lack of any mind-affecting drug use, not having special diet (herbal medicine and medicine therapy (not being professional athletes and lack of any clinical situation affects food intake in patient including: diabetes, kidney disease, thyroid, Cushing's syndrome, lupus, etc., based on the history taken from the patient.

To collect the data, a questionnaire consisting of three parts questionnaire was used: The first part was about demographic characteristics (10 questions). The second part with 30 questions focused on obsessive-compulsive disorder and the third part focused on eating disorders (EDE-Q) (28 questions).

The validity of Demographic and disease questionnaire was determined by using the method of content validity. This tool was developed by studying recent books and articles in the field of research topic. Then, they were given to 5 faculty members of Isfahan University of Medical Sciences (From different faculties: Neurology, Medicine and Nursing).

The Maudsley questionnaire was used for evaluating the obsessivecompulsive disorder [16].This questionnaire (which was answered by the person himself) was composed of 30 items with two options (true or faults). The four main categories of Maudsley questionnaire were as washing ( 11 choices), checking ( 9 choices), hesitating ( 7 choices) and doubting ( 7 choices). The scores varied from 0 to 30 and 11 score was the recognizing point, in that, any score above 11 was the sign of OCD. In all these four categories, the validity was more than 0.80 and because this test had only two options, the sensitiveness of which had been decreased remarkably. Once using the OCD scale of Dadfar et al., Iran, calculated the convergent validity as 0.87 and the validity coefficient as 0.84. Mohamad Khani, also, in 2009 made use of these very tools and had verified both the validity and reliability $[16,17]$.

Another tool used in the study was eating disorder examination questionnaire (EDE-Q) which was screen general population samples. This questionnaire included 28 items and 4 sub-tests as: having anxiety about the weight, body image, eating as well as preventing from eating. 5 point Likert's scale with responses ranging from 0 (never) to 6 (always) was used. Any score equal or more than 4 , for both the total test and the subscales, was the sign of disorder.

Validity of eating disorder examination Questionnaire (EDE-Q) was determined by content validity method in 2015 by Kordi et al. in Iran [18] and also in 2004 by Mond et al. [19]. Reliability of this questionnaire was determined in 2015 by Kordi et al. in Iran by using correlation coefficients which were $0.91,0.90,0.92,0.89,0.91$ overall and for each dimension, respectively [18].

\section{Ethical Considerations}

In this study, the tests and questionnaire designers were kept anonymous, and informed consent forms were obtained from the participants; the subjects were assured about the confidentiality of personal information. Before sampling and performing the study, permission to conduct the study was granted by university ethics committee.

\section{Data Analysis}

Data was analyzed by using SPSS statistical software version 16. Statistical analysis, we used descriptive statistics (absolute and relative frequency, mean and standard deviation) and inferential statistics (independent t-test, ANOVA and Pearson) to investigate the relationship between gender, marital status, income, level of education, job, duration of disease with OCD and eating disorder score. $\mathrm{P} \leq 0.05$ was considered as statistical significant level. 


\section{Findings}

Percentage of the patients were female (70\%) married (66.1\%), without university education (62.8\%), unemployed (67\%) and with moderate income $(63 \%)$. The highest percentage of patients $(65 \%)$ received beta-interferon as the main treatment (Table 1 ).

Mean \pm SD of eating disorder and Obsessive-Compulsive disorder scores were $4.09 \pm 0.8$ and $17.6 \pm 4.5$, respectively (Table 2 ). Also $19.1 \%$ and 48.1 of MS patients were suffering from the symptoms of eating disorder and Obsessive-Compulsive disorder respectively (Table 3).

Also the results of Pearson correlation coefficients showed that there was a statistically significant positive relationship between the overall score of OCD and eating disorder $(\mathrm{P}=0.001, \mathrm{r}=0.32)$.

The results about the relationship between the mean score of OCD and eating disorder with clinical and demographic variables were reported in (Table 4).

\section{Discussion and Conclusion}

The present study is among the first researches, which have been carried out in Iran for the survey of Obsessive-Compulsive disorder symptoms in patients with Multiple Sclerosis and its association with eating attitudes

\begin{tabular}{|l|c|c|}
\hline Variables & Number (\%) \\
\hline \multirow{2}{*}{ Gender } & Male & $60(30)$ \\
\hline \multirow{2}{*}{ Marriage } & Female & $150(70)$ \\
\hline \multirow{2}{*}{ Income } & Single & $72(33.9)$ \\
\cline { 2 - 3 } & Married & $138(66.1)$ \\
\hline \multirow{3}{*}{ Education } & Low & $55(17)$ \\
\cline { 2 - 3 } & Moderate & $80(63)$ \\
\hline \multirow{2}{*}{} & High & $65(20)$ \\
\hline
\end{tabular}

Table 1: The demographic characteristics of in MS patients participated in the study.

\begin{tabular}{|l|c|c|c|}
\hline Variable & Mean \pm SD & min & Max \\
\hline Washing & 7 & 0 & $6.1 \pm 1$ \\
\hline Doubting & 6 & 0 & $3.1 \pm 1.1$ \\
\hline Hesitating & 4 & 0 & $3.4 \pm 1.1$ \\
\hline Checking & 5 & 0 & $4.0 \pm 1.3$ \\
\hline Total score for OCD & 22 & 0 & $4.5 \pm 17.6$ \\
\hline Anxiety about body image & 1 & 0 & $1.03 \pm 0.2$ \\
\hline Anxiety about weight & 1 & 0 & $1.1 \pm 0.3$ \\
\hline Anxiety about eating & 2 & 0 & $1.4 \pm 0.1$ \\
\hline Preventing form eating & 1 & 0 & $1.1 \pm 0.2$ \\
\hline Total score for eating disorder & 6 & 0 & $4.9 \pm 0.8$ \\
\hline
\end{tabular}

Table 2: The chief criteria of eating disorder and obsessive-compulsive disorder (OCD) in MS patients.

\begin{tabular}{|l|c|c|c|}
\hline \multirow{2}{*}{ Variable } & \multicolumn{2}{c|}{ Frequency } \\
\cline { 2 - 4 } & & Absolute & Relative, \% \\
\hline \multirow{2}{*}{ Eating disorder } & Symptoms & 40 & 19.1 \\
\cline { 2 - 4 } & Without symptoms & 170 & 80.9 \\
\hline $\begin{array}{l}\text { Obsessive-compulsive } \\
\text { disorder }\end{array}$ & Symptoms & 101 & 48.1 \\
\cline { 2 - 4 } & Without symptoms & 109 & 51.9 \\
\hline
\end{tabular}

Table 3: Frequency distribution of eating disorder and obsessive-compulsive disorder (OCD) symptoms in MS patients.

\begin{tabular}{|c|c|c|}
\hline Variables & $\begin{array}{c}\text { Obsessive-compulsive } \\
\text { disorder }\end{array}$ & Eating disorder \\
\hline & $\begin{array}{c}\text { Statistical indicator, } \\
\text { P value }\end{array}$ & $\begin{array}{c}\text { Statistical indicator, } \\
\mathrm{P} \text { value }\end{array}$ \\
\hline Age & $r=0.03, p=0.5$ & $r=0.06, p=0.2$ \\
\hline Gender & $\mathrm{T}=2.2, \mathrm{df}=3, \mathrm{p}=0.2$ & $T=1.8, d f=1, p=0.3$ \\
\hline marital status* & $\mathrm{T}=6.5, \mathrm{df}=5, \mathrm{p}=0.5$ & $\mathrm{~T}=4.4, \mathrm{df}=4, \mathrm{p}=0.7$ \\
\hline Income & $f=1.4, d f=3, p=0.2$ & $f=2.7, d f=2, p=0.6$ \\
\hline Education & $T=1.3, d f=4, p=0.17$ & $T=3.3, d f=5, p=0.21$ \\
\hline Job & $\mathrm{T}=3.5, \mathrm{df}=3, \mathrm{p}=0.1$ & $\mathrm{~T}=2.2, \mathrm{df}=1, \mathrm{p}=0.4$ \\
\hline Duration of disease & $r=0.02, p=0.6$ & $r=0.05, p=0.4$ \\
\hline Type of treatment & $T=0.3, d f=5, p=0.18$ & $T=2.3, d f=8, p=0.33$ \\
\hline
\end{tabular}

Table 4: The relationship of OCD and eating disorder with demographic and disease variables in MS patients.

Of the MS patients in this study, 48.1\% had experienced the symptoms of OCD which was realized by obsessive thoughts and compulsive actions. In fact, the things which these patients acknowledged to them were as: doubting about the honesty of people, being too much serious about their works, washing things too much, checking things excessively and hesitating in even simple works. Comparing the MS patients with the control group, Shabani et al., in their studies, found that OCD was much more common amongst the MS patients than those in control group $(\mathrm{p}<0.05)(11.8 \%$ versus $2.2 \%)$ [5]. Forogipour et al., once using (Y-BOCS) questionnaire, came to the conclusion that $6.1 \%$ of patients with MS were suffering from OCD [20]. Therefore according the results of this study, in MS patients' attention needs to be paid to psychological disorders including OCD symptoms as health problems negatively impact the life satisfaction.

The other finding of this study was that $19.1 \%$ of MS patients had eating disorder symptoms. That is to say that no study, so far, has been reported, considering the eating disorder as a psychological, social, and environmental disease.

What being focused repeatedly in this research was that in spite of the fact that majority of the people in Health Caring Team consider eating disorder from the environmental aspects and many people, dealing with MS patients - believe that eating disorder is caused due to receiving different therapies, eating disorder is a sort of sociopsychological disorder. To realize the causes of eating disorder, many factors seem to be probable as: the fear of the disease threatening their personality (once being affected by MS), paying too much attention to them, the fear of the people's reaction toward their illness, and the effect of socio-cultural factors [15]. Other factors can be physical problems affecting appetite and eating behavior like diplopia, tremor, ataxia that cause the meals to get smaller.

Since the patients, in this research, also had been affected by chronic disease; therefore, it is expected that Health Caring provider take the psychological aspects of such patients into more considerations. However, the results of studies in patients with other chronic diseases showed that the majority of these patients also suffered from eating disorders. The results being found in this study were in accord with those of Hussein et al. in their study, showed that $49.4 \%$ of patients with cancer were suffering from eating disorder [15]. Also incidence of eating disorders in people with type I diabetes in John's study by using Eating Disorder Questionnaires including questionnaire of Diagnostic Survey of Eating Disorder (DSED), Eating Disorder Inventory (EDI) and Eating Attitudes Test (EAT-26 was 10\% [21].

Considering the relationship between the eating disorder and obsessive-compulsive disorder, which was one of the main aims of the present study, it was found that there was a significant positive 
relationship between the above-mentioned variables. Theretofore, Mazeo et al., also, had come to the same conclusion, focusing on the relationship between the depression and eating disorder [22]; whereas, Beker et al. had not [23]. What made the result of Bekr's study different were the different instruments he made use of. To study about the anxiety disorders such as OCD, he used the Modified ADIS- R and ADIS-IV questionnaire; however, Maudsley questionnaire was used, here. That is to say social and cultural differences can greatly influence the result, too.

It should be noted that Checking out the relationship of OCD with eating disorders in MS patients has been among distinguishing characteristics of the present study with other studies. Because it is often believed that eating changes in these patients are entirely due to the disease process or treatment complications such as methyl prednisolon (Medrol, Solu-Medrol) pulse-therapy and etc. [15]

Therefore, the results of this study can help the healthcare providers and especially the nurses that in their planning and caring of patients have a holistic perspective. They should act in their own assessments in such a manner that on the one hand, to identify disorders of OCD and eating disorder symptoms in these patients, and on the other hand, to reduce the levels of these two disorders to mitigate the consequences of physical and psychological damages in the patients and improve their quality of life [24].

\section{The Limitations}

It should be noted that the results of this study should be considered along with its limitations. In this study, changes in body weight during illness have not been investigated due to administrative problems. This study only reviewed the symptoms of eating disorders in patients and it was not possible to check the status of eating disorder based on patient weight throughout the study. In addition, another limitation of this study was the attitude of family and friends toward nutritional intakes and the history of their suffering to one of eating disorders' types and Obsessive- Compulsive disorder. In this study, due to the high volume of questions, time constraints and fatigue in patients, it was not possible to assess these variables.

Therefore, it is recommended that other researchers study about the psychological issues of eating disorder among the MS Patients. Totally the findings of this study show that psychological disorders symptoms, like eating and obsessive-compulsive disorders, are very common among the patients with MSMS. The Health Caring Team, therefore, should pay more attentions to such disorders. Such findings also emphasize in this important point that not only should the physical disabilities of MS patients be noticed and cared about, but also some other factors affecting their lifestyle as eating and obsessivecompulsive disorders should be highly noticed, too. The importance of this point becomes clear when knowing that if such disorders are recognized at their beginning stages, their undesirable signs can be prevented. In addition, Identification and early treatment on OCD and eating disorders can prevent severe symptoms of these disorders, in order to avoid situations with negative impact on the patient and even threatening the improvement of MS disease. Meanwhile, nurses who spend most of their time with MS patients have been placed in a perfect position to manage psychological disorder such as in OCD and eating disorder in MS patients. Also Nurses can improve their comprehension, understanding of these changes and the consequences that arise from them with affective and efficient treatment and care programs to take a step toward improving OCD and eating in MS patients [15].

\section{References}

1. Likert $L$ (2006) reaction to care receiving: The relationship between attachment and perceived quality of life in a sample of being helped, relationship functioning and individual with MS in Department of Psychology 2006, University of Saskatchewan Saskatoon: Saskatoon.

2. Mohamadi Razve N, Afshar (2009) Hdetermining the psychological and social factors causing stress among patients with MS. the fundamentals of mental health 10: 305-310.

3. Tinelli E, Francia A, Quartuccio EM, Morreale M, Contessa GM, et al. (2013) Structural brain MR imaging changes associated with obsessive-compulsive disorder in patients with multiple sclerosis. AJNR Am J Neuroradiol 34: 305 309

4. Khanjani Z (2012) effecting psychological factors in MS, personality traits, depression, anxiety. Medical science magezin, Tabriz 4: 60-67.

5. Shabani SA, Nikravesh LP (2010) obsessive-compulsive disorder, is it common in MS?

6. Rompella N (2009) Obsessive-Compulsive Disorder, T.U.T. Guide, Editor Scarecrow $\mathrm{Pr}$

7. Sookman D (2005) Subtypes of obsessive-compulsive disorder: Implications for specialized cognitive behavior therapy. Behavior Therap 4: 393-400.

8. Golden NH (2003) Eating disorders in adolescence and their sequelae. Best Pract Res Clin Obstet Gynaecol 17: 57-73.

9. Goebel-Fabbri AE (2009) Disturbed eating behaviors and eating disorders in type 1 diabetes: Clinical significance and treatment recommendations. Current diabetes reports 9: 133-139.

10. Dalle Grave R (2011) Eating disorders: Progress and challenges. Eur J Intern Med 22: 153-160.

11. Túry $F$, Güleç $H$, Kohls $E$ (2010) Assessment methods for eating disorders and body image disorders. J Psychosom Res 69: 601-611.

12. Safavi M, Mahamoodi M, Roshandel A (2009) Assessment of body image and its relationship with eating disorders among female students of Islamic Azad University Tehran center branch. Medical Science Journal of Islamic Azad Univesity-Tehran Medical Branch 19:129-134

13. Fitzsimmons EE, Bardone-Cone AM (2011) Coping and social support as potential moderators of the relation between anxiety and eating disorder symptomatology. Eating behaviors 12: 21-28.

14. Kaye WH, Bulik CM, Thornton L, Barbarich N, Masters K (2004) Comorbidity of anxiety disorders with anorexia and bulimia nervosa. Am J Psychiatry 161: 2215-2221.

15. Hossein SA, Bahrami M, Mohamadirizi S, Paknaad Z (2015) Investigation of eating disorders in cancer patients and its relevance with body image. Iran J Nurs Midwifery Res 20: 327-333.

16. M Dadfar AB, Malakouti SK, Bayan Zadeh S (2001) Prevalence of the Obsessive-Compulsive Disorder Symptoms. Iranian Journal of Psychiatry and Clinical Psychology.

17. Mohammad Khani SMF (2009) The Relationship of the Metacognitive Beliefs and Thought Control Strategies with Obsessive-Compulsive Symptoms in Nonclinical Population. Journal OF Clinical Psychology 1: 35-51.

18. Kordi M, Mohamadi S (2015) The assessment of eating disorder symptoms in school boys and its related with obsessive compulsive disorder. Iranian journal nursing and midwifery research.

19. Mond JM (2004) Validity of the eating disorder examination questionnair (EDE-Q) in screening for eating disorders in community samples. Behaviour research and therapy 42: 551-567.

20. Foroughipour M, Behdani F, Hebrani P, Marvast MN, Esmatinia F, et al. (2012) Frequency of obsessive-compulsive disorder in patients with multiple sclerosis: A cross-sectional study. J Res Med Sci 17: 248-253.

21. Jones JM, Lawson ML, Daneman D, Olmsted MP, Rodin G (2000) Eating disorders in adolescent females with and without type 1 diabetes: Cross sectional study. BMJ 320: 1563-1566.

22. Mazzeo SE, Slof-Op't Landt MC, Jones I, Mitchell K, Kendler KS, et al. (2006) Associations among postpartum depression, eating disorders and perfectionism in a population-based sample of adult women. Int J Eat Disord 39: 202-211. 
Citation: Mohamadirizi S (2016) The Survey of Obsessive-Compulsive Disorder Symptoms in Patients with Multiple Sclerosis and Its Association with Eating Attitudes. J Mult Scler (Foster City) 3:179. doi:10.4172/2376-0389.1000179

23. Becker Jd CB, Zayfert C (2004) Eating disorder symptoms among female anxiety disorder patients in clinical practice: The importance of anxiety comorbidity assessment. Journal of anxiety disorders 18: 255-274.
24. Rhondali W, Chisholm GB, Daneshmand M, Allo J, Kang DH, et al. (2013) Association between body image dissatisfaction and weight loss among patients with advanced cancer and their caregivers: A preliminary report. J Pain Symptom Manage 45: 1039-1049.
Citation: Mohamadirizi S (2016) The Survey of Obsessive-Compulsive Disorder Symptoms in Patients with Multiple Sclerosis and Its Association with Eating Attitudes. J Mult Scler (Foster City) 3:179. doi:10.4172/23760389.1000179
OMICS International: Publication Benefits \& Features

Unique features:

- Increased global visibility of articles through worldwide distribution and indexing

- Showcasing recent research output in a timely and updated manner

- Special issues on the current trends of scientific research

Special features:

- $700+$ Open Access Journals

$50,000+$ editorial tean

Rapid review process

- Quality and quick editorial, review and publication processing

Indexing at major indexing services

- Sharing Option: Social Networking Enabled

- Authors, Reviewers and Editors rewarded with online Scientific Credits

- Better discount for your subsequent articles

Submit your manuscript at: http://www.omicsonline.org/submission/ 